Monograph “Redefining the Digital Divide in Higher Education”

ARTICLE

\title{
Digital Inequality Among University Students in Developed Countries and its Relation to Academic Performance*
}

\author{
Jonatan Castaño-Muñoz
}

Submitted: July 2009

Accepted: October 2009

Published: January 2010

\begin{abstract}
Research on the digital divide has shown that it is important to study more than just the differences between those who do or do not have Internet access. Other dimensions that should currently be studied are: Internet skills, time spent on the Internet and, in particular, the use people make of the Internet. For each of these it is important to study the determinants and social consequences. In this paper we first present an overview of these dimensions and their determinants, and secondly analyse the influence of the dimensions with respect to the academic performance of university students. The analysed data, in agreement with international research, demonstrate that a) the effects of the Internet on academic performance are not direct, but mediated by variables and, b) the positive effects of the Internet are more pronounced in those students whose background is already more favourable for achieving better academic results without using the Internet, in agreement with the knowldege gap hypothesis.
\end{abstract}

\section{Keywords}

academic performance, digital divide, digital inequality, higher education, knowledge gap

\section{La desigualdad digital entre los alumnos universitarios de los países desarrollados y su relación con el rendimiento académico}

\section{Resumen}

La investigación sobre la digital divide ha puesto de manifiesto cómo no solo es importante estudiar las diferencias entre la gente que tiene acceso a Internet y la que no, actualmente existen otras dimensiones que cabe estudiar: babilidades en el uso de Internet, tiempo en la red y especialmente los tipos de usos que la gente hace de Internet. Igualmente, para cada una de estas dimensiones es importante estudiar sus determinantes y sus consecuencias sociales. De acuerdo con lo anterior, y llevando el campo de análisis a la infuencia de Internet en el rendimiento académico de los estudiantes universitarios, este artículo presenta en primer lugar una panorámica del estado actual de estas dimensiones y de sus determinantes para después analizar la influencia en el rendimiento académico. Los datos analizados, en consonancia con la investigación internacional, muestran

* Original title: La desigualdad digital entre los alumnos universitarios de los países desarrollados y su relación con el rendimiento académico 
cómo: a) los efectos de Internet en el rendimiento académico no son directos sino mediados por variables intermedias y, b) los efectos positivos de Internet son mayores para aquellos estudiantes con un background que favorece ya de por sí, sin la intervención de Internet, la obtención de mejores resultados académicos, o dicho de otra manera, los datos nos indican que los efectos positivos de Internet en el rendimiento académico siguen el patrón de la bipótesis del knowledge gap.

\section{Palabras clave}

rendimiento académico, brecha digital, desigualdad digital, educación superior, knowledge gap

\section{Introduction}

If we go back to the early studies on digital inequality we see how, from the beginning, the term most often used was "digital divide". This term was coined in the mid-9os, and the first time it was officially used was in the fisrt survey by the National Telecommunications \& Information Administration (NTIA) "Falling Through the Net: A Survey of the 'Have Nots' in Rural and Urban America”, (NTIA, I 995), an analysis of the dichotomy of groups which did or did not have access to and use of the Internet. With time, however, the concept has evolved from an analysis of the differences in access and effective use from a dichotomous point of view (those who do or do not have access to or use the Internet) to a more complex analysis of the differences in various dimensions between those who access the Internet, resulting in a certain conceptual ambiguity.

More recently, in search of more conceptual clarity, some authors have proposed the term "digital inequality" (Di Maggio et al, 2004) as a better definition of the social inequality related to the appearance of the Internet and its incorporation and use in society getting over the semantic dichotomy and the imprecision of the term "digital divide". The term "digital inequality" takes into account all the dimensions which have become included in the concept of digital divide, and includes a social vision of the technology which goes beyond the differences in the defined dimension. The term also takes into account the determinants and the resulting social implications, so allowing exploration of the construction of inequality through the combination of technical and social resources. This exploration requires explanatory models which distinguish between different modes of use and adoption of the Internet and directly linking behaviour to the social and institutional context where they take place.
Attempts have been made (Van Dijk and Hacker, 200o; Hargittai, 2002; Di Maggio et al, 2004; Van Dijk, 2006) to define the dimensions of inequality and the digital divide, and there is some agreement that at least four are key factors: access which includes the motivational differences for the first move towards ITC (motivational access) as much as the differences in access to technological infrastructure (the classic digital divide), digital literacy, the different skills for Internet use, intensity of use (differences in the time of use) and finally, the purpose of use of the Internet by individuals (differences in adopting the Internet and behaviour).

The concept of digital inequality referred to in this paper refers to these four dimensions, a concept which is central for the two objectives:

- Present an overview of the state of each dimension of digital inequality in universities in developed countries and establish what their determinants are.

- Analyse the role played by each of the aforementioned dimensions and the relations between them in studying the syllabus content outlined by higher education institutions, that is, the academic performance of the students.

To achieve these objectives, this paper is mainly based on various analyses (some published, some in process and some not published) of the data of the "University and Network Society" project, the aim of which was to identify and analyse Internet use in the Catalan university community, particularly in the area of education and the repercussions. In addition, the contrasting and amplifying of the results with international research in the area are also presented, without the intention of giving an exhaustive theoretical revision. In this way, although the majority of the results

I. The report of investigation in Catalan can be found at: http://www.uoc.edu/in3/pic/cat/universitat_societat_xarxa.html. A summary in English can be found at: http://www.uoc.edu/in3/pic/eng/university_network_society/report.html 
presented deal with the local situation in Catalonia, contrasting them with international research may allow for a more general analysis of developed countries.

The results presented here, more than basic research, are important for public educational policies and more so at a time when the way of using the Internet is being discussed in the European Space for Higher Education and when there is still time to attenuate, as much as possible, the social inequalities in the digital world and their propagation. However, it is important to state that the analyses presented which link digital inequality to learning are mainly focussed on acquiring knowledge for the syllabus designed by higher education institutions, meaning that it does not take into account acquiring other skills which could be very useful in the information society but are not incorporated or assessed in tests on academic performance.

\section{Digital inequality among university students}

This point describes the current state of the four dimensions which make up digital inequality: access, digital literacy, intensity of use and purpose of use. Given that the differences in each of the dimensions are not distributed randomly, we review the determinants for these dimensions in Catalonia, and compare them with international research.

\section{I. Access to the Internet: Motivation, infrastructures and place of connection}

Analysing the difference in access to the Internet (both motivational and in infrastructure access) it can be seen that they are practically of no significance in the university community. There is little published on the effects of motivation in university students, but Bozionelos (2004) has demonstrated that, in this group too, socioeconomic status is related to "computer anxiety', with students from families with lower socioeconomic status more likely to have negative emotions when using a computer, one of the reasons why they use the Internet less. Despite this, those who have a motivational barrier to connecting to the Internet are without a doubt a minority not quantified in any study.

Focussing on the differences of access to infrastructures, we see that virtually all students have their own ways of accessing the Internet, in contrast to the situation in other educational levels (Huang and Russell, 2006). In state universities in Catalonia, in the 2005-2006 academic year, more than $91 \%$ of students had their own computer with Internet connection. The data are corroborated by other studies in developed countries which demonstrate that, among university students, the classic digital divide, referring to who has or has not access to the Internet, is irrelevant. This is normal considering that university students have two of the basic characteristics which augur connection to the Internet: youth and a high academic level.

With a more detailed analysis, some differences are seen regarding the kind of device used for Internet access. In Catalonia we see that $43 \%$ of university students use a laptop since when the Catalonia Internet Project (2006) was being carried out, there was a tendency among students to switch from desktops to laptops. However, other devices for accessing the Internet were emerging, the mobile phone the most widely used one representing $6.85 \%$ of Internet users. When it comes to the bandwidth used, more than $90 \%$ of the students connect to the Internet via broadband connections, in this way greatly limiting the differences between broadband users and users of conventional connections, such as the time spent online, the greater number of activities carried out and the higher level of content creation by those using broadband (Matthews and Schrum 2003).

As well as their own connections, the students generally have Internet access at an institutional level. Universities in developed countries have arranged for the necessary infrastructures to be within reach of the university community, with sufficient technological facilities for the small minority who do not have their own computer with Internet connection. In Spain, for example, the student to computer ratio decreased from 24 in the year 2000 to $\mathrm{I} 2$ in 2003 (OCDE, 2005).

The differences in the devices used, and having an own connection or depending on public facilities for access, have repercussions on autonomy in Internet use. An own connection and portable devices offer more autonomy as to the location for connecting to the Internet which some studies (Asanni, 2006 in Hargittai and Hinnant, 2008) have correlated with uses considered beneficial for increasing personal capital, such as the search for information on health, products, shopping online, banking etc.

To summarise, university students in developed countries, in general, do not have major differences with respect to connection infrastructures and almost all are able to use their own broadband, with a minority having an advantage or disadvantage with respect to the level of autonomy of connection. But does this mean that they can all derive the same benefit from Internet? Is equal access sufficient to make sure that the degree in which students are able to benefit from Internet use (for improving academic per- 
formance as well as in other areas) ceases to be a cause of existing social inequality but rather of personal inequalities and options?

As various studies have demonstrated (e.g. Neuman and Celano, 2006), while the playing field - access to technological resources - is levelled in a student group, the advantages that each individual takes of these are not equal, and it may even cause an increase in the differences between advantaged and disadvantaged groups as a result of other variables. Having technology is not sufficient for social transformation and the reduction of inequalities, as, in contrast to the thesis defended by technological determinism, technologies alone have not been the motor of social change. Social, institutional, and ultimately human problems are factors which can result in failure of any improvement initiative, in any environment, which is based on ICT (Warschauer, 200I). This is why it is interesting to go further and study what is known as the "second level of digital divide" (Hargittai, 2002): the differences in skills and uses between people who use the Internet, including university students.

\subsection{Digital literacy: differences in Internet skills}

The data on Catalan university students demonstrate that the level of Internet skills in the university community is very high compared to the general population. Within Catalan universities, only $7.35 \%$ of students claim to have an elementary or basic level (the 2 lowest levels on a scale of 5) while 5 r. $55 \%$ claim to have a high or expert level. However, it is interesting to study who has the best user skills, looking at whether there are specific characteristics which influence these skills. Once again, our analysis of Catalan university students gives some clues to this, indicating that, while this is a more homogeneous collective than the rest of the population, there are still differences between the students.

There are differences with respect to the variables which determine the way technological skills are acquired: formal and informal learning. In agreement with other studies (Tien and $\mathrm{Fu}, 2008$ ) our data show how the most effective way of increasing Internet skills is to study a degree where the syllabus incorporates computer skills (with all other variables being equal, engineering students have most skills and humanities students the least). This is followed by informal self-study, which shows that a lot of time on the Internet leads to skills improvement (Hargittai and Hinnant, 2008). Therefore it is normal that those students in Catalonia who have more years of experience in using the Internet, those who use it more than five days a week, and those who spend many hours a day online, have better Internet skills than other students.

In society there also exist differences as a result of maintaining social roles over generations, of gender as much as socioeconomic status, and it is important to see what role they play in digital literacy. Firstly, with respect to gender, it can be seen that, excluding all other variables (including those, such as women being in the minority in technological studies, which could introduce major bias), women are still at a disadvantage in acquiring skills which goes further than formal education and has more to do with the persistence of cultural stereotypes and social roles linking man with technological knowledge. This is consistent with studies in other countries such as Taiwan (Tien and $\mathrm{Fu}, 2008)$. Secondly, with respect to socioeconomic status, it is noticeable that, again with all other variables taken into account, the socioeconomic status of the family, measured by the education and profession of the parents, does not influence the acquisition of technological skills. It would therefore seem that the hypothesis of cultural reproduction does not apply to the acquisition of technical skills in university students in the online society. There are two explanations for this. One is the major cultural and economic homogeneity of the families of university students compared to the population in general, as the system works against children from less favoured families at earlier stages in their education so they are less likely to reach higher education. The second explanation is that parents do not have technological skills as part of the cultural capital they can transmit to their children as they are part of a generation who grew up without the Internet and at most they are "digital immigrants" normally with a low level of skills (Prensky, 200I).

In spite of this there is evidence that socioeconomic status plays an indirect role in acquiring technological skills, reaffirming the importance of formal education. The fact is that students from private secondary schools have better skills, because, as shown by Mominó et al. (2008), even though state schools in Catalonia have more technological resources, they are less effectively used both in the syllabus and in strategic plans.

\subsection{Time online: The intensity of Internet use}

Another dimension of the inequalities of Internet use which appears in the literature is intensity or time spent online. Analysing the results available, as with skills, the university students as a group show higher levels of connection and more frequent and intensive use of the In- 
ternet (Katz, 2005). Once again, the explanation lies in two defining characteristics of the students: their high educational level and youth. This is confirmed by a study in Catalan universities, which shows that $79.5 \%$ of the students connect to the Internet five, six or seven days a week and only r. $59 \%$ one or less days a week. With respect to the duration of the connections, $\mathrm{I} 7 \%$ of the students say their daily session on the Internet last less than one hour, $6 \mathrm{I} .49 \%$ between I and 3 hours, and $2 \mathrm{I} .05 \%$ more than 3 hours. If we look at which variables are related to greater use, the results for Catalan university students are consistent with international research in the following aspects: again there is a digital divide in favour of men (Chen and Peng, 2008), and it is clear that the students with better connection (ADSL), those who connect from home and those with better skills, are those who spend more time online (Hargittai and Hinnant, 2008).

But how can these differences in time of use be explained? Do the variables listed in the previous paragraph have a direct relation to the time spent or is there an intermediate variable which helps explain the relationship? It seems clear that at least one intermediate variable exists as much of the literature shows that the time of use is linked to the purpose of going online (Kubey et al, 200I; Howard et al, 2002; Matthews and Scrum, 2003; Chen and Peng, 2008), and this is no different in Catalan universities. It is not the aforementioned characteristics, therefore, which directly explain the time of use, but rather the reasons for using the Internet, which is the intermediate variable. We go on to analyse these differences in purposes of use among students.

\subsection{Adopting the technology: purpose of use of the Internet}

What activities do university students do when they are online? The study of Catalan universities has led us to the conclusion that they use the Internet for ends other than those specifically related to being a student, not forming a specific user group but along the same lines as those of young people in general in Catalonia (Castells et al, 2007). This means that their main use of the Internet is related to leisure, communication and downloading files, with a special use of time to play online games and use of realtime communication systems. These results are in agreement with most studies in developed countries (Kubey et al, 2001; Jones, 2002; Matthews and Schrumm, 2003; Tien and $\mathrm{Fu}, 2008$; Hargittai and Hinnant, 2008), where the use of Internet does not in itself form part of a university student culture, while in less developed countries, where Internet access is only available through university con- nections, the use is more academic, in this case forming part of the student culture (Tella, 2007). With respect to educational use, which is part of the student culture, it is seen to take up a small amount of time spent online, with the only exception being to communicate with other students, which is also a social use and not necessarily done for educational purposes. A main reason for this low use is the lack of incorporation and use of Internet tools in the teaching-learning process by educational institutions (Duart et al, 2008).

Up to now, the dynamics which the student follows, in general, with respect to the purpose for using the Internet have been discussed, but, as always in analyses of the digital divide, it is important to look at whether differences exist as a function of certain characteristics. Some differences have been shown to exist. In the study by Peter and Valkerburg (Peter and Valkerburg, 2006 in Claro, M., 2007), they show how students with the highest socioeconomic status use the Internet more to obtain information and less for entertainment, also shown to be the case for students in Catalan higher education. Differences in use have also been detected depending on gender (Ying and Fang, 2008), with women using it more for academic purposes, communication and shopping, while men use it more for games, searching for adult content and looking for more general information.

If we focus on one of the most recent innovations on the web, the Web 2.0, we also see that differences in use exist among university students. The data for Catalan students are in agreement with those of a study by Hargittai and Walejcko (2008) and show how, in spite of the age homogeneity among the students, age as a variable plays a major role in the case of innovations, with younger students using the Web 2.0 more frequently. We also see that the socioeconomic status of the family, taken as the cultural and economic level of the student's parents, also has an influence on the use of the Web 2.o. The cultural capital transmitted by these parents may have a relation to the creation of social networks, collaborative work and an entrepreneurial spirit, elements which have an influence on the more innovative and social adoption of the Internet which the use of the Web 2.0 implies, and which now already forms part of the habitus of the upper classes.

\section{Digital inequality and academic performance}

Having analysed the state of the four dimensions of digital inequality and the determinants of the differences existing 
in each one, we move on to the second objective, and take a further step by analysing the consequences these differences may have in student learning. We focus in particular on the students' academic performance related to the syllabus content set by higher education institutions.

The analysis of Internet access shows how infrastructures alone have no effect on students' academic performance (Neuman and Celano, 2006; Warschauer, 200I and 2008), while the place where Internet is used should be taken into account. According to the data for Catalonia, the few students who only connect from the university have better academic results than those who do so from more locations. This is because the use they make of the university connection is largely related to academic work. This produces an interesting situation where the restricted autonomy imposed by the faculty leads indirectly to at least one positive consequence: improved performance. This is confirmed by a study at the University of Botswana (Tella, 2007) where it was found that students who most use the Internet are those with the better academic performance as, in contrast to students in developed countries, their main point of connection is at the university and so the use is generally for academic purposes and not leisure.

With respect to the level of digital literacy, having a high level of Internet skills does not have a negative effect on academic performance, more likely positive provided these skills are integrated in the syllabus. We will see that certain sophisticated uses of the Internet, such as participating in Web 2.0 or advanced searches, can have a positive effect on performance. Taking into account that a certain level of skill is required for these sophisticated uses, an indirect positive effect of the skills on academic performance can be observed, leading us to assume they are a necessary requisite for specific uses.

Research shows how the different reasons for using the Internet and the time dedicated online do have an effect on academic performance. Use for leisure purposes such as chats and online games may have negative effects, but, once again, they are not direct but mediated by other variables such as spending the time needed for academic activities on leisure activities. A peak is found in those students who are addicted to Internet leisure activities, which leads to an excessive amount of time spent online as well as psychological disorders such as sleeplessness, social isolation and depression, factors which have a direct influence on academic performance (Kubey et al, 200r, Chen and Peng, 2008). Several publications describe how these effects only occur in the minority of people who spend an excessive amount of time online, and that the negative relation to academic performance is not linear, but increases dramatically after a high threshold. This means that negative effects are not clearly seen in the majority of students, and in the literature there are cases where positive effects on academic performance have been seen mediated by the improvement in information handling and communication skills (Gil Flores, 2009), teamwork (Ramboll Managament, 2006 in Claro, 2007) and self-study (Law, 2006). These indirect effects of non-academic use of the Internet explain findings such as those in the PISA report where, although at the secondary level, excluding all other variables, the academic performance of those students who use the Internet the least and the most is lower than those who use it moderately (Claro, 2007). As such, it would seem that, in contrast to general belief, the use of the Internet for leisure purposes may have a positive effect on academic performance when it is within certain limits, not too low, and, in particular, not too high.

Concerning the academic use of the Internet, various studies show that, in general, academic performance is improved (Tien and Fu, 2008), but it is still important, as always, to deal with general terms in greater detail, as this use of the Internet does not directly mean performance improves. Another study indicates that various conditions must be met for this improvement to occur (Castaño and Duart, 2008). The first is that the student is interested in learning. This is not as evident as it may seem, as the academic performance of those students who try use the Internet to make studying easier and to pass exams, not to learn, is worse than that of other students. The second condition is that the higher education institution integrates Internet use within its pedagogical framework. If not, there exists the risk that groups of students with a learning style favouring Internet use, even though they are eager and willing to learn, come up against a university teaching methodology which does not value the skills for this type of learning. As a result, as well as the possible lack of motivation which could result from not being able to use the Internet in the classroom (Balanskat et al, 2006), they are likely to get worse academic results.

The strategy for academic use of the Internet which most clearly increases academic performance is to follow the teaching-learning methodology of the university (whatever it may be, classic or innovative in the use of technologies), and complement this with another strategy obtained through social uses of the Internet which are designed for academic purposes (Fuchs and Woesmann, 2004; Castaño and Duart, 2008). In this strategy the intermediate variable between the use of the Internet and academic performance is the interest or will of the student 
to increase their knowledge, but also to share and discuss with other interested students. In this case, the use of the Web 2.o for learning could be useful technology to channel this curiosity and extend what is learnt on the syllabus. A good strategy for using Internet resources for self-learning may well be to combine these resources by an initial guided teaching method. The institutional "guide" can help with the basic knowledge necessary to move on to self-study, and once this has been achieved learning should be promoted through more social and collaborative networks, along the lines of e-learning 2.0 (Downes, 2005), so that students can acquire more expert knowledge in their field of study, on their own.

\section{Conclusions}

University students are a more homogeneous collective than the population in general (at least when considering the academic level, socioeconomic status and age), but major differences can still be seen in their relation with the Internet. As such, it is also important to study different aspects of digital inequality, its determinants and its consequences, in this collective.

Connection to the Internet is available to all students in developed countries, and the majority of them have a personal connection and so a high level of autonomy. But access to infrastructures is not sufficient to guarantee equal opportunities for all students, as in the other dimensions of digital inequality (skills, intensity and purposes) there are differences in function of a number of variables discussed in this paper, which could have an important role in relation to academic performance.

Possibly the most interesting relation is that which links the different purposes of Internet use with academic performance. To reduce the inequality generated herein, it is necessary to know which uses are and are not beneficial for improving academic performance, as well as their determinants. The data presented in this paper are in line with the "knowledge gap" hypothesis, which postulates that those students most advantaged in the knowledge of the Internet are those who then take most advantage of it, here, the greatest improvement in academic performance. This is the case because having better Internet skills as well as being from a family with high socioeconomic status are good determinants of more sophisticated uses and furthest from the dynamics of leisure uses by the young population in general. This is beneficial for the individual, it favours what Hargittai and Hinnant have called "capital-enhancing uses" (Hargittai and Hinnant, 2008).
Among the beneficial uses which increase the capital of the students in our study, one which stands out for its major usefulness in improving academic performance is using the Internet as a social medium to extend, share and discuss the information obtained in formal education. However, this use is not randomly distributed within the population, but is found more in students who have more Internet skills and who come from families with a high socioeconomic status, recreating the habits typical of their social class (handling information, constructing a network of contacts, discussion groups, etc.). This confirms Van Dijck's (2005) hypothesis of the appearance of a "usage gap" which separates those who use the Internet for leisure purposes and those who use it for work and education. Therefore, although the usage skills are not directly conditioned by the family cultural capital, the student's types of uses are. Social dynamics are maintained, putting those students who use the Internet for leisure at a greater disadvantage, as they will have worse academic results because they have less time to dedicate to academic tasks, have less benefits from good use of the Internet (although it should be remembered that moderate use may result in some indirect benefit, albeit less than from proper academic use) and they run a greater risk of suffering from the negative effects due to excessive use, such as addiction and all its consequences.

As we have shown, the explanation for the relation between the Internet and academic performance is always influenced by determinants and with intermediate variables. It is in the study of these two factors where we think the emphasis should go for future research, away from the search for a direct relation with technological determinism. Variables such as student interest in extending, sharing and discussing knowledge, the extra motivation of using the Internet in the classroom, the time set aside for academic tasks and that dedicated to using the Internet, addiction to the Internet and its psychological consequences, the improvement of information handling, communication, teamwork and self-study skills, are some of the variables which are considered important in the mediation between the uses of Internet and academic performance. But it is important to continue along these lines to move toward the construction of a model that can explain the relationship, not to consider it as a black box at which untested hypotheses are launched.

Moving forward with knowledge on the relationship between the Internet and academic performance could be of great use for public educational policies. Empirical studies have already demonstrated that simply having technology available does not provide equal opportunities for all 
students, that it is necessary to go further and ensure that all have the same skills to enable sophisticated uses and the interest in uses which are shown to be beneficial. This is where planners and educational institutions have to see which measures are most useful for encouraging awareness and bolstering advanced digital literacy and for carrying out these uses, particularly in the most disfavoured groups of students. It is also sure that progress along these lines of research will result in new challenges leading to social improvement.

\section{Bibliography}

BALANSKAT, A.; BLAMIRE, R.; KEFALA, s. (2006). The ICT impact report. A review of studies of ICT impact on schools in Europe [report online]. European Schoolnet. European Commission.

$<$ http://insight.eun.org/shared/data/pdf/impact_ study.pdf>

BOZIONELOS, N. (2004): Socio-economic background and computer use: the role of computer anxiety and computer experience in their relationship. International Journal of Human-Computer Studies. Vol. 6r, no. 5, pp. $725-746$.

CASTAÑO, J.; DUART, J. M. (2008). "Uses of internet and academic performance in the Catalan university system”. In: International Conference on Information Communication Technologies in Education (July 2008: Corfu, Greece) [communication online].

<http://www.icicte.org/ICICTEo8_Proceedings. htm>

CASTells, M.; TUbella, I.; SANCHO, T.; ROCA, M. (2007). La transición a la sociedad red. Barcelona: Ariel.

CHEN, Y.; PENG, s. s. (2008). “University students' Internet use and its relationships with academic performance, interpersonal relationships, psychosocial adjustment, and self-evaluation". Cyberpsychology \& Behavior. Vol. I I , no. 4, pp. 467-469.

ClARO, M. (2007). "Information and communication technologies and educational performance". In: $C E-$ RI-KERIS International Expert Meeting on ICT and Educational Performance (I6-I7 October 2007: Cheju Island, South Korea) [communication online]. <http://www.oecd.org/dataoecd/o/r 9/394857 I 8.pdf>

Dimaggio, P.; hargitTAi, E.; Celeste, C.; Shafer, s. (2004). "From unequal access to differentiated use: a literature review and agenda for research on digital inequality" [report online]. <http://www.eszter.com/research/pubs/dimaggioetal-digitalinequality.pdf>

DOWnes, s. (2005). "E-learning 2.0" [article online]. eLearn Magazine.

<http://www.elearnmag.org/subpage.cfm?section=arti cles\&article $=29^{-} \mathrm{I}>$

DUART, J. M.; GIL, M.; PUJOL, M.; CASTAÑO, J. (2008). La universidad en la sociedad red. Barcelona: Ariel.

Fuchs, T.; WoEsmanN, L. (2004). "Computers and student learning: bivariate and multivariate evidence on the availability and use of computers at home and school". CESifo Working Paper. No. I 32 I. Category 4: Labour Markets.

Gil flores, J. (2009). "Computer use and students' academic achievement" [communication online]. In: $R e^{-}$ search, Reflections and Innovations in Integrating ICT in Education. M-ICTE 2009 proceedings.

<http://www.formatex.org/micte2009/book/ I 29II $295 \cdot \mathrm{pdf}>$

HARgitTAi, E. (2002). "Second level digital divide: differences in people's online skills" [article online]. First Monday. Vol. 7, no. 4.

<http://firstmonday.org/issues/issue7_4/hargittai>

HARgittai, E.; Hinnant, A. (2008). Digital inequality. Differences in young adults' use of the Internet. Communication Research. Vol. 35, no. 5, pp. 602-62 I.

hargittai, E.; WAlejKo, g. (2008). "The participation divide: content creation and sharing in the digital age". Information, Communication and Society. Vol. I I, no. 2, pp. $239^{-2} 56$.

$<$ http://www.webuse.org/the-participation-dividecontent-creation-and-sharing-in-the-digital-age/>

HOWARD, P. E.; RAINIE, L.; JONES, s. (2002). "Days and nights on the Internet". In: B. WELLMAN; C. HAYTHORNTHWAITE (ed.). The Internet in everyday life $\mathrm{Ox}^{-}$ ford: Blackwell Publishing. Pp. 45-73.

HUANG, J.; RUSSEll, s. (2006). The digital divide and academic achievement. The electronic library. Vol. 24, no. 2, pp. I60-I73.

JONES, s.; MADDEN, M. (2002). The Internet goes to college: how students are living in the future with today's technology [report online]. Washington DC: Pew Internet \& American Live Project.

<www.pewinternet.org/PPF/r/7 I/report_display.asp>

KATZ, J.E.; RICE, R. E. (2006). "Consecuencias sociales del uso de Internet”. In: Nuevas tecnologías y sociedad. Barcelona: UOC.

KUBEY, R. W.; LAVIN, M. J.; BARROWS J. R. (2OOI). "Internet use and collegiate academic performance decrements: early findings". Journal of Communication. Vol. 5 I, no. 2, pp. 366-382. 
LAW, N. (2007). "Comparative international evidence on the impact of digital technologies on learning outcomes: tentative findings from SITES 2006 and related studies". In: CERI-KERIS International Expert Meeting on ICT and Educational Performance (I6-I7 October 2007: Cheju Island, South Korea) [communication online].

<http://www.oecd.org/dataoecd/o/33/39482643.pdf> matthews, D.; schrum, L. (2003): High speed Internet use and academia gratifications in the college residence. Internet and Higher education. Vol. 6, no. 2, pp. I 25 -I 44 .

mominó, J. M; sigALÉs, c.; meneses, J. (2008). L'escola a la societat xarxa. Barcelona: Ariel.

NATIONAL TELECOMMUNICATIONS \& INFORMATION ADMinistration (NTIA) (I 995). Falling through the net: a survey of the "bave nots" in rural and urban America [survey online].

$<$ http://www.ntia.doc.gov/ntiahome/fallingthru. html>

Neuman, s.; CElano, D. (2006). The knowledge gap: implications of leveling the playing field for low-income and middle-income children. Reading Research Quarterly. Vol. 4I, no. 2, pp. I76-20I.

oCDE (2005). Analyse des politiques de l'education. Regards sur l'enseignement supérieur. Édition 2005-2006. Paris: OCDE.

PRENSKY, M. (200I). "Digital natives, digital immigrants" [article online]. On the Horizon. Vol. 9, no. 5. [Accessed: 09/04/08].
$<$ http://www.marcprensky.com/writing/Prensky\%20 -\% 20 Digital\% 20 Natives, \% 20 Digital\% 2 oImmigrants\%20-\%2oPartı.pdf>

TELLA, A. (2007). "University of Botswana undergraduates uses of Internet: implications on academic performance". Journal of Educational Media E' Library Sciences. Vol. 45, no. 2, pp. I6 I-I 85 .

TIEN, F. F.; FU, T. T. (2008). "The correlates of the digital divide and their impact on college student learning”. Computers and education. Vol. 50, no. I, pp. $42 \mathrm{I}-436$.

VAN DIJK, J. (2005). The deepening divide. London: Sage.

VAN DIJK, J. (2006). "Digital divide research, achievements and shortcomings". Poetics. Vol. 34 , no. 4-5, pp. 22 I235 .

VAN DIJK, J.; HACKER, K. (2000). "The digital divide as a complex and dynamic phenomenon". In: $50^{\text {th }}$ Annual Conference of the International Communication Association (I-5 June 2000: Acapulco) [communication online].

<http://www.gw.utwente.nl/vandijk/research/digital_divide/Digital_Divide_overigen/pdf_digitaldivide_website.pdf>

WARSCHAUER, M. (200I). "Reconceptualizing the digital divide" [article online]. First Monday. Vol. 7, no. 7 . <http://firstmonday.org/htbin/cgiwrap/bin/ojs/index. $\mathrm{php} / \mathrm{fm} /$ article/view/967/888>

WARSCHAUER, M. (2008). "Laptops and literacy: a multisite case study". Pedagogies: An International Journal. Vol. 3, no I, pp. 52-67.

\section{Recommended citation}

Castaño-muñoz, jonatan (20I0). "Digital Inequality Among University Students in Developed Countries and its Relation to Academic Performance". In: "Redefining the Digital Divide in Higher Education” [online monograph]. Revista de Universidad y Sociedad del Conocimiento (RUSC). Vol. 7, no. r. UOC. [Accessed: dd/mm/yy]. <http://rusc.uoc.edu/ojs/index.php/rusc/article/view/v7nI_castano/v7ni_castano> ISSN $1698-580 \mathrm{X}$

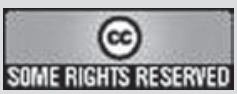

This work is subject to a Creative Commons Attribution-Noncommercial-NoDerivative-Works 3.o Spain licence. It may be copied, distributed and broadcasted provided that the author and the source (Revista de Universidad y Sociedad del Conocimiento - RUSC) are cited. Commercial use and derivative works are not permitted. The full licence can be consulted at: <http://creativecommons.org/licenses/by-nc-nd/3.o/es/deed.en> 


\author{
About the author \\ Jonatan Castaño-Muñoz \\ Researcher at the Internet Interdisciplinary Institute $\left(\mathrm{IN}_{3}\right)$ \\ $\mathrm{IN}_{3}$ - Universitat Oberta de Catalunya \\ Av. Canal Olimpic, s/n. Edifici B3. \\ Parc Mediterrani de la Tecnologia. \\ o886o Castelldefels (Barcelona), Spain \\ jcastanomu@uoc.edu
}

Degree in Political Science and Administration. Masters in Applied Social Research. He was a researcher on the Project Internet Catalonia ${ }^{\text {www }}$ and is co-author of the book La universidad en la sociedad red published by Ariel. He is currently doing research in the field of technology and education, focussing on digital inequality of students in higher education and its relation to academic performance. He is completing his doctoral thesis at the Internet Interdisciplinary Institute $\left(\mathrm{IN}_{3}\right)$ of the Universitat Oberta de Catalunya (UOC), with a grant from the UOC.

[wwwI] (http://www.uoc.edu/in3/pic/esp/)

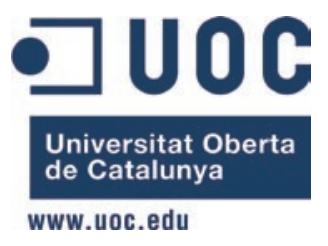

